\title{
The Business-Automated Data Economy Model Shifted Towards Sustainability, 2018 Update
}

\author{
Dumitru-Alexandru Bodislav ${ }^{1}$, Amelia Diaconu², Marcela Mitriță $\breve{3}^{3}$
}

\begin{abstract}
This research is based on an algorithm developed for the American stock market for increasing the efficiency of closed funds, which had as secondary output a suitable and sustainable model that could be partially scaled to fit issues regarding automated decision making at government level, similar to a basic Business Intelligence solution (follows similar procedures like the workflow of IBM Cognos), which offers a solution in cutting to best suitable path for making a governmental decision, e.g.: if a country needs investment in roads infrastructure, healthcare or education, by using the principles behind this simple model you could yield the results and come to the best solution or best fitted regarding the global economic output. The model is based on companies traded on NASDAQ and LSE because they offer the best suitable cases for transparency, credible auditing and also it emulates the economic sectors that form a nationwide economy. The synergy between Big Data analysis, BI practices and processing power could lead to new business designed by investment banks and complex software developers: the business of automated decision making to reduce the paths that could be followed in developing a country or a private investment. In the following paper we highlight an update developed on a research started 8 years ago which developed into a fully operational economic model.
\end{abstract}

Keywords: Emerging markets, bubble, model performance, artifical intelligence, macroeconomic output.

\section{Introduction}

The literature review discusses the impact of the research by offering all the sides of the proposed research. The literature review also analyses the technological influence on developing the Gross Domestic Product and how it could be moulded into a model by selecting similar sectors as those that form a modern economic system. The methodology presents the processes through which the model was developed and how the companies were selected. This section also includes the technical perspective on how an economy is partitioned into its main economic sectors by using the GICS classification. By implementing some changes to the GICS sector classification it helps our model to better understand how influential sectors and constituents are in order to specifically clarity how the model works. In addition, the methodology also highlights how advanced and emerging economies performed over the same sample period and how main stock market indicators reacted to the macroeconomic environment through the lifespan of the Business-Automated Data Economy Model (BDM), the updated version from mid 2018 (Bodislav, 2015a, 2015b, 2016, 2017, 2018). In particular, the analysis focuses from the end user's perspective as a unique result and also analyse the sectorial evolution of the model. The conclusion opens the door for future research on

\footnotetext{
| ${ }^{1}$ Associate Professor PhD, Bucharest University of Economic Studies, Bucharest, Romania

${ }^{2}$ Lecturer PhD, Artifex University, Bucharest, Romania

| $3 \mathrm{PhD}$ Candidate, Bucharest University of Economic Studies, Bucharest, Romania
} 
the subject and contemplates on technological evolution and the macroeconomic reordering created by the actual information era that we live in and also highlights the next turning point for the global economy, who'll be the next weak link, either the technological bubble, or the emergent markets wave.

\section{Updating the Business-Automated Data Economy Model (MID 2018 Edition)}

The proposed model (B.D.M.) tries to improve the efficiency of closed funds by developing an algorithm which uses data from the US stock market. The secondary output is to use the same algorithm as a model which is scaled to fit and solve issues regarding automated decision making at government level. All these solutions are filtered from the Business Intelligence perspective of software algorithms similar to those found in solution like IBM Cognos. Our proposed model helps capture large amounts of data in order to provide viable solutions for decision making particularly when simulating an entire nationwide economy. It represents a new vantage point on the traditional view of economic growth and the idea of developing a pseudo-economy that replicates how a country functions. To achieve this, many companies which capture and represent the broad economy are included. These companies operate in many different sectors as classified by GICS sector classification methodology. Global Industry Classification Standard has classified the sectors as follows (GCIS, 2015): Energy, Materials, Industrials, Consumer Discretionary, Consumer Staples, Health Care, Financials, Information Technology, Telecommunication Services and Utilities. In particular, companies used to create the model (B.D.M.) are listed on NASDAQ OMX exchange.

BDM is developed by analysing how the economy works from the entities that form it, from the sectors that through its business processes develop to form a nationwide economy. The companies that form the BDM also underline the difference between profit and welfare (the purpose of a company versus the purpose of a government or state). Practically, the efficiency of companies represents the backbone of the developed model and validates this research.

To develop a country in a successful and functional manner you need to surpass the unification processes, the national consciousness and the historical dependence that usually form a nation and go further than the event horizon. Macroeconomic performance shows in a relative way how economic evolution is ignited in a country, however the quality and living standards are also important details in the path of development.

When developing the proposed economic model, we initially evaluated companies which were most appropriate for the economic model that were most influential and representative of a modern nationwide economy. For this to be possible we needed to use a transparent and open market which also has transaction costs reduced to minimum level, both tasks being complied by NASDAQ OMX. We used the advantages offered by NASDAQ OMX (as operational platform) and Bloomberg Professional as the service that provides analytical data that is relevant to our research to help us retrieve data in order to build our model. Before all these could be used we needed to select the main sectors that form a functional economy that is in line with the latest trends of the $21^{\text {st }}$ century, so this is why we sliced the main macroeconomic sectors into ten. Using the 
GICS classification as a basis we modified some sectors accordingly to better fit our model, however modified the sectors because we needed to reach the actual volatile status of a modern economy. For instance, the Financials sector was divided into two sectors: Financial and Derivatives. The Consumer Discretionary sector was renamed as Cyclical Consumption sector because of the faster rate of consumption, the goods and services that form this sector have a higher replacement rate. The Consumer Staples sector was also modified as Non-Cyclical Consumption sector because of a lower rate of consumption of those types of goods and services. Our modified sectors are: Materials, Derivatives, Telecommunication Services, Cyclical Consumption, Non-Cyclical Consumption, Energy, Industrials, Financial, Information Technology and Utilities. The Financial and Derivatives form the tertiary sector that is seen as the money flow side of an economy. The aggregate demand is based on the evolution of the Telecommunication Services, Cyclical Consumption, Non-Cyclical Consumption, Information Technology, Energy and Utilities sectors. These sectors offer consumers end products and services. Furthermore, they also enter the creation of aggregate supply when they enter the production process providing intermediary goods or services as is the case in the Materials and Industrials sectors. The companies used to form the model are traded on NASDAQ OMX and where selected by using the investment service offered by Zacks Investment Management (the Value Investor and Insider Trader solutions - Zacks, 2015a, Zacks, 2015b), this way simulating the services offered by all investment companies to corporate clients. The 58 companies that form the economic model are representative to emulate and simulate a nationwide economy and its sectors, but are not representative for the NASDAQ OMX platform, which includes more than 3000 companies. The 58 companies were selected from a review of publicly available data about their financial performance, by suiting them with the previously mentioned sectors and by analysing their potential to grow.

The selection of the companies that form the model was based on a previous research conducted in 2011 (Bodislav, 2013). This selection process is however explained and justified in more detail in the following pages. The companies were selected by using the solution utilised by investment companies like Zacks Investment Research (Zacks, 2015a and Zacks, 2015b) and Goldman Sachs (Goldman Sachs Outlook, 2015). The former uses both the Insider Trader solution (Zacks, 2015b) and Value Investor (Zacks, 2015a) solution. These are custom tailored to the needs of investors who have theoretical knowledge of the domain, but require further assistance with the practical aspects. The selection was initially made in August - September 2011 timeframe using the solutions specified previously. The execution interval for the model was chosen based on the idea that the global economy is in a continuous muddling through process and considering that the model's execution is based on stock flow on a competitive market created especially for them. The stock' prices include also investors' optimism and the fact that almost all chosen companies are listed in the U.S., on the NASDAQ OMX platform.

Going further in building the pseudo-macroeconomic model (the Business-Automated Data Economy Model - B.D.M.) the following companies were used: 
Table 1. Companies that round up the Business-Automated Data Economy Model, 2018 updated edition

\begin{tabular}{|c|c|c|c|c|c|c|c|}
\hline Number & Company Name & Indicator & State & Business Profile & 22.06 .2018 & 3.10 .2011 & Delta 18/11 \\
\hline 1. & Schweitzer-Mauduit International & SWM & Georgia & Premium paper & 43,43 & 27,57 & 57,53 \\
\hline 2. & Paramount Gold and Silver Corp. & PZG & Nevada & Rare metals mining & 1,33 & 2,17 & $-38,71$ \\
\hline 3. & Goldcorp Inc & GG & Canada & Rare metals mining & 13,72 & 45,36 & $-69,75$ \\
\hline 4. & First Majestic Silver Corp & $\mathrm{AG}$ & Canada & Silver mining & 7,65 & 14,9 & $-48,66$ \\
\hline 5. & SPDR Gold Trust & GLD & UK & ETF & 120,34 & 160,96 & $-25,24$ \\
\hline 6. & Telefonica SA & TEF & Spain & Telecom & 8,67 & 18,38 & $-52,83$ \\
\hline 7. & Stamps.com & STMP & California & Delivery services & 252,65 & 19,36 & 1205,01 \\
\hline 8. & OpenTable & OPEN & California & Online Reservations & 0,00 & 0,00 & 0,00 \\
\hline 9. & Google Inc. & GOOG & California & Internet Search \& SAAS & 1155,48 & 495,52 & 133,19 \\
\hline 10. & Watsco & WSO & Florida & AC technologies & 181,61 & 51,31 & 253,95 \\
\hline 11. & Town Sports International Holdings & CLUB & New York & Fitness & 11,95 & 6,87 & 73,94 \\
\hline 12. & Steven Madden & SHOO & New York & Footwear & 53,15 & 28,36 & 87,41 \\
\hline 13. & Ross Stores & ROST & California & Discount Stores & 85,98 & 38,21 & 125,02 \\
\hline 14. & Nordstrom & JWN & Washington & Fashion Retailer & 51,43 & 45,37 & 13,36 \\
\hline 15. & Men's Wearhouse & MW & Texas & Men's suits & 0,00 & 0.00 & 0,00 \\
\hline 16. & Maidenform Brands & MFB & North Carolina & Fashion \& Retail & 0,00 & 0.00 & 0,00 \\
\hline 17. & LuLulemon Athletica & LULU & Canada & Technical Fashion & 124,18 & 44,8 & 177,19 \\
\hline 18. & Watson Pharmaceuticals & WPI & Nevada & Pharmaceuticals & 0,00 & 0.00 & 0,00 \\
\hline 19. & Techne Corporation & TECH & Minnesota & Biotechnology & 161,46 & 65,29 & 147,30 \\
\hline 20. & On Assignment & ASGN & California & HR Specialized Solutions & 81,20 & 6,75 & 1102,96 \\
\hline 21. & Jazz Pharmaceuticals & JAZZ & Ireland & Pharmaceuticals & 178,50 & 37,35 & 377,91 \\
\hline 22. & Cross (A.T.) Company & ATX & Rhode Island & Writing instruments & 0,00 & 0.00 & 0,00 \\
\hline 23. & Western Refining & WNR & Texas & Refining & 0,00 & 0,00 & 0,00 \\
\hline 24. & Sunoco Logistics Partners & SXL & Pennsylvania & Oil 360 & 25,18 & 29,46 & $-14,53$ \\
\hline 25. & Patterson-UTI Energy & PTEN & Texas & Energy production & 18,06 & 15,83 & 14,09 \\
\hline 26. & Exxon Mobil Corporation & $\mathrm{XOM}$ & Texas & Energy (exploration \& production) & 81,38 & 71,15 & 14,38 \\
\hline 27. & Alon USA Energy & ALJ & Pennsylvania & Petrol (production \& distribution) & 0,00 & 0.00 & 0,00 \\
\hline 28. & Templeton Russia Fund & TRF & Florida & Financial derivate & 0,00 & 0.00 & 0,00 \\
\hline 29. & Tanger Factory Outlet Centers & SKT & North Carolina & REIT & 23,92 & 24,73 & $-3,28$ \\
\hline 30. & Rayonier Inc. & RYN & Florida & Building materials & 38,30 & 35,65 & 7,43 \\
\hline 31. & Plum Creek Timber Company & PCL & Washington & Wood industry & 0,00 & 0.00 & 0,00 \\
\hline 32. & Medallion Financial Corp. & MFIN & New York & Financial taxi business & 5,70 & 8,91 & $-36,03$ \\
\hline 33. & CME Group Inc & $\mathrm{CME}$ & Illinois & Trading \& Investment Banking & 168,42 & 49,7 & 238,87 \\
\hline 34. & Berkshire Hathaway $(1 / 100)$ & $\mathrm{BRK} / \mathrm{A}$ & Nebraska & Business Solutions & 2865,41 & 1047,01 & 173,68 \\
\hline 35. & Bank of America Corporation & $\mathrm{BAC}$ & North Carolina & Banking \& financial services & 28,99 & 5,53 & 424,23 \\
\hline 36. & American Campus Communities Inc & ACC & Texas & REIT & 43,08 & 36,15 & 19,17 \\
\hline 37. & Westinghouse Air Brake Technologies Corporation & WAB & Pennsylvania & AC technologies & 100,70 & 50,15 & 100,80 \\
\hline 38. & \begin{tabular}{|l|l|} 
MasTec \\
\end{tabular} & \begin{tabular}{|l|} 
MTZ \\
\end{tabular} & Florida & Building grounds & 52,10 & 16,93 & 207,74 \\
\hline 39. & GSI Group / Novanta & GSIG/NOVT & Massachusetts & Lasers \& Electro-optical solutions & 62,50 & 7,27 & 759,70 \\
\hline 40. & Grupo Aeroportuario del Sureste & \begin{tabular}{|c|} 
ASR \\
\end{tabular} & Mexico & Aeroports & 159,00 & 48,94 & 224,89 \\
\hline 41. & General Electric Company & GE & Connecticut & Technology \& Financial Services & 13,05 & 14,69 & $-11,16$ \\
\hline 42. & Embraer-Empresa Brasileira de Aeronautica & ERJ & Brazil & Aviation 360 & 25,62 & 24,67 & 3,85 \\
\hline 43. & Colfax Corporation & CFX & Maryland & Pipelines & 30,32 & 19,07 & 58,99 \\
\hline 44. & Boeing Company & $\mathrm{BA}$ & Illinois & Aviation development & 338,91 & 58,25 & 481,82 \\
\hline 45. & Bae Systems Plc & BAESY & UK & Aerospace \& Defense Systems & 33,60 & 15,78 & 112,93 \\
\hline 46. & 3M Company & MMM & Minnesota & Technology Company & 196,50 & 70,93 & 177,03 \\
\hline 47. & Goldman Sachs Income Builder Fund A Shares & GSBX & New York & Mutual funds & 0,00 & 0.00 & 0,00 \\
\hline 48. & Ultratech & UTEK & California & Innovation & 0,00 & 0.00 & 0,00 \\
\hline 49. & Stratasys & SSYS & Minnesota & $3 \mathrm{D}$ printers & 19,00 & 18 & 5,56 \\
\hline 50 & Microsoft Corporation & MSFT & Washington & IT & 100,41 & 24,53 & 309,34 \\
\hline 51. & j2 Global & JCOM & California & Cloud Computing \& SAAS & 88,31 & 25,5 & 246,31 \\
\hline 52. & International Business Machines Corporation & IBM & New York & BI \& Technical Innovation & 141,28 & 173,29 & $-18,47$ \\
\hline 53. & Intel Corporation & INTC & California & \begin{tabular}{|l|l} 
Microprocessors \& chipsets \\
\end{tabular} & 52,50 & 20,62 & 154,61 \\
\hline 54. & CACI International & CACI & Virginia & Enterprise Information Technology & 171,95 & 46,81 & 267,34 \\
\hline 55. & Apple Inc * & AAPL & California & \begin{tabular}{|l|l} 
PCs \& multimedia devices \\
\end{tabular} & 1109,52 & 374,57 & 196,21 \\
\hline 56. & ACI Worldwide & ACIW & Nebraska & Electronic Payments & 26,01 & 25,26 & 2,97 \\
\hline 57. & 3D Systems Corporation & DDD & South Carolina & $3 \mathrm{D}$ printers & 14,32 & 13,5 & 6,07 \\
\hline 58. & American Water Works & AWK & New Jersey & Utilities - water works & 83,42 & 29,27 & 185,00 \\
\hline & \multirow[t]{2}{*}{ TOTAL } & & & SUM & 6117,46 & 3510,68 & \multirow[t]{2}{*}{134,98} \\
\hline & & & & AVERAGE & & 74,25 & \\
\hline
\end{tabular}

The companies with yellow background were initially listed on the stock market, but they were bought and taken full private once again, e.g.: Open Table, Men's Wearhouse, Maidenform Brands, Watson Pharmaceuticals, Cross (A.T.) Company, Plum Creek Timber Company, Ultratech, Western Refining and Alon USA Energy. Templeton Russia Fund and Goldman Sachs Income Builder Fund were initially part of the model, however the closed fund reached their maturity and were subsequently closed by 
Templeton and Goldman Sachs.

Source: investment fund created to simulate an economy and with the purpose to create growth. All companies are listed on NASDAQ, except Grupo Aeroportuario del Sureste and Embraer-Empresa Brasileira de Aeronautica which are a Mexican company and a Brazilian company, both of them being listed as ADRs.

To validate the model's performance and not to consider it a "black swan" exception (Taleb, 2010), the model was circulated for three and a half years and this way it included expectations that were decreased all over the world. Obtaining economic growth that gravitates around zero value sends a disturbing message to all advanced economies. Reaching the debt limit for the US in 2013 and in 2017 and validating as a solution eliminating the debt ceiling on an undefined period of time sent the world economy in an unrealistic booming period. The FED through its Quantitative Easing (1, 2 and 3) and Operation Swap programs and seconded by the European Central Bank through the QE program injected cheap money that ignited Consumption in developed economies.

\section{Conclusion}

The big picture represents the idea of the Information Economy in the Digital Era and going from analogous consumers (based on traditional experiences when it comes to satisfying their needs through demand that is met by supply in a certain given space, be it a store, bank, generally known as the market place) towards digitally filtered consumers (they are satisfied by solutions created in the virtual market place, online or in augmented or virtual reality). The digital advance and bias towards digital has as main features decreasing production costs that imply policies similar to "just in time manufacturing" stock management created by Toyota in the "70s and in the long run representing upscale lowering prices, and because demand is evaluated without error and estimated in line with consumer's needs, the counterpart, the producer's supply will have an immediate response and this way the stocks of goods will be very close to zero. All these results seen as the bigger picture form a great competitive advantage: the optimization of consumer anticipation. At microeconomic level we have individual clients, such as large corporations for B2B relationships and at macroeconomic level we deal with countries that function like hyper-corporations. These must attract new investors, such as other corporations and other states. The attractiveness is created by an optimized labour force which involves individuals who accept offers that others do not.

Although in previous research done by the same author the emphasis was towards a burst of the bubble on the IT\&C sector, these days after seeing the results of the model, we could state that IT\&C sector reached a level of self-awareness that helps it to get auto-regulated and could survive in a tensioned bubble for a longer period of time, but in the same time we have the emerging markets that are hype at this moment, over-flooded with investments and have the potential to create their own wave that could turn into a tsunami of economic and financial disruptiveness. The long game will oblige to include game changers like Artificial Intelligence that could lead to disruptions in the economic environment and could shift small countries in becoming global players, as an example we have Saudi Arabia and the fact that they gave citizenship to a limited self-aware robot Sophia, that evolved in 6 months from limited functionality and interaction to limited 
self-awareness, and which on June 2018 went on having a semi-functional body, so the path to a functioning android that is self-aware and can interact with human is a part of the near future and which could bring sustainability of the economy, life and the environment to a new unforeseen level.

\section{References}

Bloomberg Professional service. (2018). http://www.bloomberg.com/markets

Bodislav, D. A. (2016). Business Intelligence for Decision Making in Economics. In Dunis, C., Middleton, P., Karathanasopolous, A., Theofilatos, K. (Eds.) Artificial Intelligence in Financial Markets, (pp. 125158). London: Palgrave Macmillan.

Bodislav, D.A. (2015a). Transferring business intelligence and big data analysis from corporation to governments as a hybrid leading indicator, Theoretical and Applied Economics, vol. 22, no. 1(602), 257264.

Bodislav, D. A. (2015b). The Big Data - Business Intelligence Synergy. The Solution for Building Relevant Indicators for an Emerging Economy, Bucharest: ASE Publishing.

Bodislav, D. A. (2013). The optimal corporative model for sustainable economic growth for an emergent country, Bucharest: ASE Publishing.

Bodislav, D. A., Bran, F., Popescu, L. (2018). The Business Automated Data Economy Model, 2018 early update, Quality - Access to Success, vol. 19, no. s1, 80-84.

Bodislav, D. A., Dinu, M. (2017). Internet based Technologies versus Emerging Markets - which bubble will burst first?, European Economy and Digital Society in the Current Geopolitical Context (EEDS 2017), 16-18 November, Ploiesti, Romania.

Global Industry Classification Standard. (2015). https://en.wikipedia.org/wiki/Global_Industry _Classification_Standard

Taleb, N.N. (2010). Lebăda Neagră - Impactul foarte puțin probabilului, Bucharest: Curtea Veche Publishing.

Zacks Investment Management Value Investor. (2015a). http://www.zacks.com/valueinvestor/?adid =TOP_ONLINE_NAV

Zacks Investment Management Insider Trader. (2015b). http://www.zacks.com/insidertrader/ 